\title{
CARACTERIZAÇÃO ESTRUTURAL DE AÇOS INOXIDÁVEIS AUSTENIITICOS SUSCEPTÍVEIS AO EFEITO TRIP QUANDO SUBMETIDOS A BAIXOS GRAUS DE REDUÇÃO VIA LAMINAÇÃO ASSIMÉTRICA*
}

\author{
Lucas Barbosa Balthazar \\ Carolline Serafim da Silva² \\ Monica Aline Magalhães Gurge/ ${ }^{3}$ \\ Saulo Brinco Diniz \\ Alaelson Vieira Gomes ${ }^{5}$ \\ Luiz Paulo Mendonça Brandao 6 \\ Andersan dos Santos Paula
}

\section{Resumo}

Os aços inoxidáveis devido suas propriedades e vasta aplicação vêm sendo analisados em busca de maximizar o seu potencial, dentre as séries mais estudadas estão a 300 e a 200 que se diferenciam pela composição química. Neste trabalho analisou-se a imposição de baixos e distintos graus de redução (até 10\%) pela laminação assimétrica de aços inoxidáveis austeníticos 304L e 201LN, possíveis transformações martensíticas induzidas por deformação no material, efeito TRIP, a fim de avaliar a formação de martensita em função da assimetria da deformação e ao longo da espessura do material. Confirmando os resultados esperados através de análises no microscópio eletrônico de varredura, e de macro e microdureza.

Palavras-chave:Laminação assimétrica; Efeito TRIP; Aço inoxidável austenítico.

\section{STRUCTURAL CHARACTERIZATION OF AUSTENITIC STAINLESS STEEL SUSCEPTIBLE TO TRIP EFFECT WHEN SUBJECT TO SMALL DEGREES OF REDUCTION VIA ASYMMETRIC ROLLING}

\begin{abstract}
The stainless steels due to their properties and wide application have been analyzed to improve your potential, among the most studied series are 300 and 200 that differ by chemical composition. This project studies small and distinct degrees of reduction (10\% maximum) by asymmetric rolling of $304 \mathrm{~L}$ and $201 \mathrm{LN}$ austenitic stainless steels, subjected to transformation induced plasticity, known as TRIP effect, in order to evaluate martensite formation in function of the strain asymmetry in sheets thickness. Confirming the expected results through analysis in scanning electronic microscope, macro and microhardness.
\end{abstract}

Keywords: Asymmetric rolling; TRIP effect; Austenitic stainless steels.

1 Graduando em Eng. Metalúrgica, Seção de Engenharia de Mecânica e Materiais (SE/4), Instituto Militar de Engenharia (IME), Rio de Janeiro, RJ, Brasil.

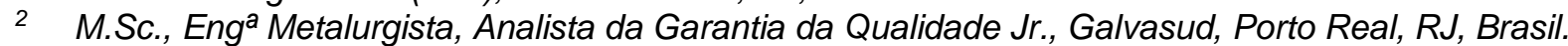

3 M.Sc., Eng ${ }^{a}$ Metalurgista, Doutoranda em Ciência dos Materiais do Programa de Pós-Graduação em Ciência dos Materiais (PGCM), SE-4 / IME, Rio de Janeiro, RJ, Brasil.

4 M.Sc., Eng o Metalurgista, Doutorando em Ciência dos Materiais do Programa de Pós-Graduação em Ciência dos Materiais (PGCM), SE-4 / IME, Rio de Janeiro, RJ, Brasil.

5 D.Sc., Engo Metalurgista, Professor Adjunto do PGCM e da Graduação, SE-4, IME, RJ, Brasil.

6 D.Sc., Engo Metalurgista, Professor Associado do PGCM e da Graduação, SE-4, IME, RJ, Brasil.

7 D.Sc., Eng ${ }^{\underline{a}}$ Metalurgista, Professora Adjunto do PGCM e da Graduação, SE-4, IME, RJ, Brasil. 


\section{INTRODUÇÃO}

Os aços inoxidáveis diferem-se dos aços comuns por possuírem uma maior resistência à corrosão em função de sua composição química, o que implica que eles possam ser aplicados em situações nas quais os comuns não são indicados [1]. De acordo com os elementos de ligas adicionados e por consequência a microestrutura final tem-se as diferentes famílias desse grupo de materiais. $\mathrm{Na}$ tabela 1 tem-se exemplificado alguns aços inoxidáveis de acordo com sua composição química.

\begin{tabular}{|c|c|c|c|c|c|c|c|c|c|c|c|}
\hline \multirow{2}{*}{$\begin{array}{l}\text { Designacäa } \\
\text { Outokumpu }\end{array}$} & \multicolumn{4}{|c|}{ Designação internacional } & \multicolumn{7}{|c|}{ Composiçăo quimica f́pica, $\%$} \\
\hline & EN & ASTM & UNS & JIS & $c$ & $\mathbf{N}$ & cr & Ni & & Mo & Outros \\
\hline \multicolumn{12}{|c|}{ Graus de aços inoxidáveis ferríticos } \\
\hline 4003 & 1.4003 & - & $\$ 40977$ & - & 0.02 & & 11.5 & 0.5 & & & \\
\hline 4000 & 1.4000 & $410 \mathrm{~s}$ & $\$ 41008$ & SUS 403 & 0.03 & & 12.5 & & & & \\
\hline 4010 & 1.4010 & 430 & $\$ 43000$ & Sus 430 & 0.05 & & 10.2 & & & & \\
\hline 4521 & 1.4521 & 444 & $\$ 44400$ & SUS 444 & 0.02 & & 18 & & & 2 & $\mathrm{Ti} \mathrm{Nb}$ \\
\hline \multicolumn{12}{|c|}{ Graus de aços inoxidaveis duplex } \\
\hline LDX $2101^{\circ}$ & 1.4162 & - & 532101 & - & 0.03 & 0.2 & 21.5 & 1.5 & 0.3 & & $5 \mathrm{MnCu}$ \\
\hline LDX $2404^{*}$ & $1.4662^{4}$ & - & S82441 & - & 0.02 & 0.27 & 24 & 3.6 & 1.6 & & $3 \mathrm{MnCu}$ \\
\hline 2205 & 1.4462 & - & $532205^{2}$ & SUS329J3L & 0.02 & 0.17 & 22 & 5.7 & 3.1 & & \\
\hline 2507 & 1.4410 & - & $\$ 32750$ & - & 0.02 & 0.27 & 25 & 7 & 4 & & \\
\hline \multicolumn{12}{|c|}{ Graus de aços inoxidáveis austeniticos } \\
\hline 4310 & 1.4310 & 301 & $\$ 30100$ & SUS 301 & 0.10 & & 17 & 7 & & & \\
\hline 4372 & 1.4372 & 201 & $\$ 20100$ & Sus 201 & 0.05 & 0.20 & 17 & 4 & & & $7 \mathrm{Mn}$ \\
\hline 4301 & 1.4301 & 304 & 530400 & Sus304 & 0.04 & & 18.1 & 8.1 & & & \\
\hline 4401 & 1.4401 & 316 & 531600 & SUS316 & 0.04 & & 17.2 & 10.1 & 2.1 & & \\
\hline \multicolumn{12}{|c|}{ Graus de aços inoxidáveis austeníticos de alta performance } \\
\hline $904 \mathrm{~L}$ & 1.4539 & SO4L & NC89O4 & - & 0.01 & & 20 & 25 & 4.3 & & $1.5 \mathrm{Cu}$ \\
\hline 254 SUO $^{\infty}$ & 1.4547 & - & 531254 & SUS312L & 0.01 & 0.20 & 20 & 18 & 6.1 & & $\mathrm{Cu}$ \\
\hline 4529 & 1.4529 & - & NC8926" & - & 0.01 & 0.20 & 20.5 & 24.8 & 6.5 & & $\mathrm{Cu}$ \\
\hline 4565 & 1.4565 & - & 534565 & - & 0.02 & 0.45 & 24 & 17 & 4.5 & & $5.5 \mathrm{Mn}$ \\
\hline $654 \mathrm{SuO}^{*}$ & 1.4652 & - & 532654 & - & 0.01 & 0.50 & 24 & 22 & 7.3 & & $3.5 \mathrm{MnCu}$ \\
\hline \multicolumn{12}{|c|}{ Graus de aços inoxidáveis austenificos em alta temperatura } \\
\hline $253 \mathrm{Mh}=$ & 1.4835 & - & \$30815 & - & 0.09 & 0.17 & 21 & 11 & & & $1.6 \mathrm{SiCe}$ \\
\hline 4845 & $1.4845^{2}$ & $310 \mathrm{~S}^{2}$ & 531008 & SUS 310 S & 0.05 & & 25 & 20 & & & \\
\hline
\end{tabular}

Os aços inoxidáveis austeníticos (AIA) constituem a família de maior importância, além da resistência a corrosão, possuem boa soldabilidade e boas propriedades mecânicas. Nesta família encontra-se a série 300 cujo o aço mais comum é o do tipo 304, pertence a um sistema $\mathrm{Fe}-\mathrm{Cr}$ - Ni, destacando-se das demais devido a sua excelente combinação de propriedades e, consequentemente, ampla gama de aplicações [3]. Apesar de possuírem propriedades incontestáveis, os aços da série 300 apresentam como desvantagem o custo elevado de produção, principalmente, em função da adição de níquel [4]. Assim, com o objetivo de se obter um aço com um custo inferior e que pudesse substituí-los em certas aplicações, desenvolveu-se a série 200 de sistema Fe-Cr-Mn-N, com adições reduzidas de níquel e adição combinada de nitrogênio e manganês como seus substitutos na função de preservar a estrutura austenítica. Estes aços são comumente denominados pelo seu teor de níquel, como por exemplo "4\%Ni" referente ao tipo 201 [5]. Alguns deles podem apresentar LE até 30\% superior ao do aço 304, fazendo com que sua aplicação em estruturas mais leves seja possível $[6,7]$.

Sabe-se que os AIA não são endurecidos por tratamentos térmicos, pois os elementos de liga presentes reduzem a temperatura de início de transformação para 
valores sub-zero, dificilmente atingidos (equação 1), onde $M_{i}$ é a temperatura de início de transformação induzida termicamente [8]:

$$
\mathbf{M}_{\mathbf{i}}\left({ }^{\circ} \mathbf{C}\right)=1305-41,7 \% \mathrm{Cr}-61,1 \% \mathrm{Ni}-33,3 \% \mathrm{Mn}-27,8 \% \mathrm{Si}-
$$

Alternativamente, a presença de austenita à temperatura ambiente, e uma baixa energia de falha de empilhamento, menor que $18 \mathrm{~mJ} / \mathrm{m}^{2}$ (equação 2), resulta em um favorecimento da transformação direta $\gamma \rightarrow \alpha^{\prime}$ [8].

$$
\begin{gathered}
E F E(m J / m 2) \\
=-53+0,7(\% C r)-6,2(\% N i)-3,2(\% M n)+9,3(\% M o)
\end{gathered}
$$

Tal processo de transformação pode ocorrer quando o material é deformado, sendo assim ambos os aços analisados são passíveis de efeito TRIP (Transformation Induced Plasticity), ou seja, são metaestáveis de forma que a transformação martensítica pode ser induzida por tensão ou deformação, acarretando em uma alta capacidade de encruamento e alta resistência mecânica, em função da temperatura e das características da solicitação mecânica. Mas o qual é limitado por uma temperatura máxima para formação de Martensita por deformação (Md), a qual é complexa para se estimar, e na prática estima-se a temperatura onde $50 \%$ de martensita se forma a partir da aplicação de 30\% de deformação verdadeira (Md30) - conforme equação 3 [9].

$$
\begin{gathered}
M d 30\left({ }^{\circ} C\right)=413-462(C+N)-9,2 S i-8,1 M n-13,7 C r-9,5 N i \\
-18,5 M o
\end{gathered}
$$

Estes aços apresentam excelente capacidade de absorção de energia, a qual é essencial para muitas aplicações, especialmente na indústria automotiva [10,11]. Como esse efeito promove a formação de martensita quando o material sofre deformação plástica, isso poderá ser resultado de um processo de laminação simétrica ou assimétrica, por exemplo, onde este último foi proposto no presente trabalho. A laminação simétrica consiste na deformação plástica do material, podendo ser realizada a frio ou a quente, onde esse é forçado entre dois rolos rotatórios de mesmo diâmetro, que comprimem o corpo causando uma redução em sua espessura. $O$ processo de laminação assimétrica ocorre da mesma maneira, porém os rolos que causam a redução têm dimensões diferentes entre si $[12,13,14]$.

\section{MATERIAIS E MÉTODOS}

As amostras de AIA fornecidas pela empresa APERAM South America pertencente à série 300 e a série 200, cuja suas respectivas composições químicas estão descritas na Tabela 2.

Tabela 2: Composição dos aços inoxidáveis estudados.

\begin{tabular}{|c|c|c|c|c|c|c|c|c|c|}
\hline $\begin{array}{l}\text { Elementos } \\
\text { \% peso })\end{array}$ & $\mathrm{C}$ & $\mathrm{Mn}$ & $\mathrm{Si}$ & $\mathrm{V}$ & $\mathrm{Nb}$ & $\mathrm{Cr}$ & $\mathrm{Ni}$ & $\mathrm{Mo}$ & $\mathrm{N}$ \\
\hline $304 \mathrm{~L}$ & 0,0196 & 12,617 & 0,4911 & 0,0490 & 0,0086 & 180,363 & 80,837 & 0,1351 & 0,0509 \\
\hline $201 \mathrm{LN}$ & 0,0300 & 69,078 & 0,3088 & 0,0428 & 0,0224 & 170,043 & 40,093 & 0,0188 & 0,2000 \\
\hline
\end{tabular}

Essas amostras foram analisadas via microscopia eletrônica e ensaios de macrodureza e microdureza, após sofrerem um processo de laminação assimétrica a 
quente com a finalidade de verificar como se comportaria a dureza e microestrutura após esse processamento. Para a laminação assimétrica foi utilizado um laminador piloto do fabricante FENN MFG. Co., modelo D-51710:1973, que encontra-se instalado no Laboratório de Processamento Mecânico do IME. O laminador foi operado na configuração quádruo (com quatro cilindros, sendo dois cilindros de trabalho e dois cilindros de encosto), no qual os cilindros de encosto são os mesmos utilizados na laminação simétrica e os cilindros de trabalho com 54,8 mm e $32,8 \mathrm{~mm}$ de diâmetro, obtendo-se uma razão de assimetria de 1,67. Após a laminação assimétrica fez-se a preparação metalográfica onde as amostras foram lixadas nas seguintes granulometrias: 220, 400, 600, 800, 1000, 1200 e 1500 mesh, seguido de um polimento eletrolítico em uma solução de ácido perclórico e álcool etílico com composição em volume de 4:1, utilizando uma tensão de $15 \mathrm{~V}$ e um tempo médio de 50 segundos, posteriormente fez-se um ataque utilizando uma solução de ácido oxálico (10\%) com uma tensão de $12 \mathrm{~V}$ e um tempo médio de 15 segundos.

$\mathrm{Na}$ Tabela 3 tem-se a características das amostras após a laminação assimétrica com suas respectivas denominações que serão utilizadas ao longo do trabalho.

Tabela 3. Características das amostras após laminação assimétrica.

\begin{tabular}{|l|c|c|c|c|c|c|}
\hline \multirow{2}{*}{ Amostra } & \multicolumn{3}{|c|}{ Aço 210LN } & \multicolumn{3}{c|}{ Aço 304L } \\
\cline { 2 - 7 } & I & II & III & IV & V & VI \\
\hline Espessura Inicial (mm) & 5,00 & 5,00 & 5,00 & 6,40 & 6,40 & 6,40 \\
\hline Número de passes & 1 & 2 & 2 & 1 & 2 & 2 \\
\hline Redução por passe (\%) & 10 & 5 & 5 & 10 & 5 & 5 \\
\hline Giro & - & Não & Sim & - & Nao & Sim \\
\hline $\begin{array}{l}\text { Denominação utilizada } \\
\text { no trabalho para cada } \\
\text { condição }\end{array}$ & $\begin{array}{c}\text { AIA2LA10 } \\
\text {-P1 }\end{array}$ & $\begin{array}{c}\text { AIA2LA05 } \\
-P 2\end{array}$ & $\begin{array}{c}\text { AIA2LA05 } \\
-P 2 G\end{array}$ & $\begin{array}{c}\text { AIA3LA10 } \\
-P 1\end{array}$ & $\begin{array}{c}\text { AIA3LA10 } \\
-P 1\end{array}$ & $\begin{array}{c}\text { AIA3LA05 } \\
\text {-P2G }\end{array}$ \\
\hline
\end{tabular}

Para a análise de macrodureza foram realizadas 5 medidas com auxílio de um equipamento de dureza Rockwel C (HRC) com penetrador cônico de diamante, précarga de $10 \mathrm{kgf}$ por $15 \mathrm{~s}$ e uma carga de $150 \mathrm{kgf}$. A microdureza foi realizada em um equipamento da Shimadzu HMV-G com carga de $100 \mathrm{gf}$, sendo as medidas dessa propriedade realizadas em pontos distintos da espessura das amostras (1/4, 1/2 e 3/4 da espessura - em 3 pontos para cada região da espessura). Ambos os equipamentos estão instalados no Laboratório de Ensaios Mecânicos do IME

\section{RESULTADOS E DISCUSSÃO}

Com bases nas características composicionais e microestruturais dos aços em estudo espera-se que ambos tenham uma evolução microestrutural semelhante, mas com intensidade distinta de formação de martensita. Tendo em vista seus valores de Mi e EFE, calculados com base nas equações 1 e 2 da introdução deste trabalho:

- Aço 201LN: Mi $\left(-271,1^{\circ} \mathrm{C}\right), \operatorname{Md} 30\left(-23,4^{\circ} \mathrm{C}\right)$ e EFE $\left(6,0 \mathrm{~mJ} / \mathrm{m}^{2}\right)$.

- Aço 304L: Mi $\left(-114,2^{\circ} \mathrm{C}\right), \operatorname{Md} 30\left(39,3^{\circ} \mathrm{C}\right)$ e EFE $\left(15,2 \mathrm{~mJ} / \mathrm{m}^{2}\right)$.

\subsection{Macrodureza}

Uma das caracterizações realizada foi a macrodureza Rockwell C (HRC). Como apresentado na Figura 1, onde se observa que o aço 201LN apresentou uma macrodureza superior à do aço 304L esse fato é consequência da composição química, pois possui teores incrementados de $\mathrm{C}, \mathrm{Mn}$ e $\mathrm{N}$ em relação ao aço da série 
300. O manganês incrementa o coeficiente de encruamento do aço $201 \mathrm{LN}$ quando comparado ao 304L, o que irá refletir na dureza. Sendo que o resultado obtido vem a corroborar com os resultados do trabalho prévio de Silva em relação as amostras como recebidas [15]. No entanto, a relação de incremento da dureza macro entre as amostras processadas com um único passe de 10\% (LA10-P1), 2 passes de $5 \%$ sem giro (LA05-P2) e 2 passes de $5 \%$ com giro (LA05-P2G) foram distintos entre os aços 304L (AIA3) e 201LN (AIA2). Este comportamento pode estar associado a heterogeneidade de deformação ao longo da espessura do material e medidas em faces distintas entre as faces da chapa em contato com os cilindros de menor e maior diâmetro durante a laminação assimétrica.

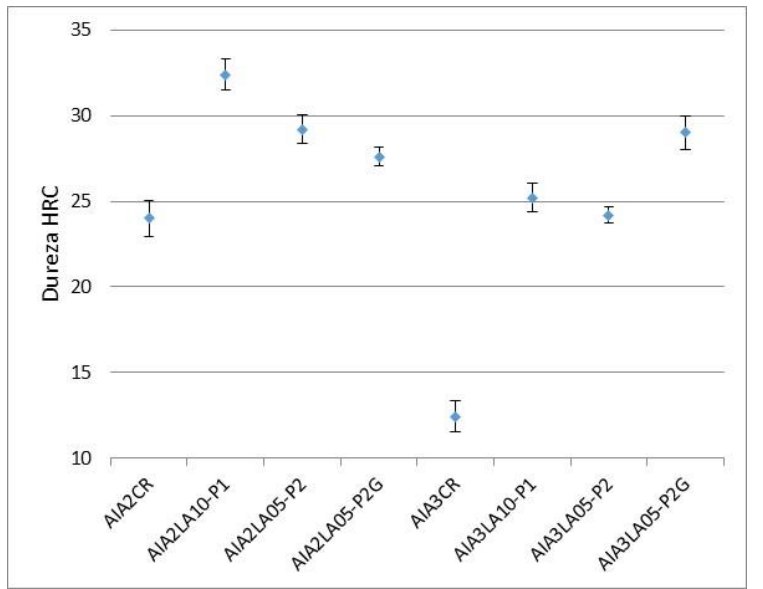

Figura 1. Ensaio de macrodureza Rockwell C das amostras.

\subsection{Microdureza}

Os resultados de microdureza obtidos para as amostras são apresentados no gráfico da Figura 2 para ambos os aços submetidos a único passe de $10 \%$ de redução na espessura durante a laminação assimétrica. Novamente os resultados das análises da amostra como recebida foi obtido em trabalho prévio de dissertação de mestrado de Silva [15], onde a mesma utilizou para as essas análises uma carga de $20 \mathrm{gf}$ em um ultramicrodurômetro instrumentado com indentador Vickers. Conforme esperado, observa-se para o aço 201LN uma tendência de incremento da microdureza ao longo da espessura para 2 passes de $5 \%$ sem giro (AIA2LA05-P2) e homogeneização para 2 passes de $5 \%$ com giro (AIA2LA05-P2G). Enquanto um único passe de 10\% (AIA1LA10-P1) tem um comportamento inesperado de menor dureza no centro da espessura. Por outro lado, no aço $304 \mathrm{LN}$ verifica-se ao contrário: um incremento da microdureza ao longo da espessura para 1 passe de 10\% (AIA3LA10-P1) e um menor valor no centro da espessura para 2 passes de $5 \%$ sem giro (AIA3LA05-P2). Mantendo-se o comportamento de tendência a homogeneização para 2 passes com 5\% com giro (AIA3LA05-P2G), conforme o esperado. 

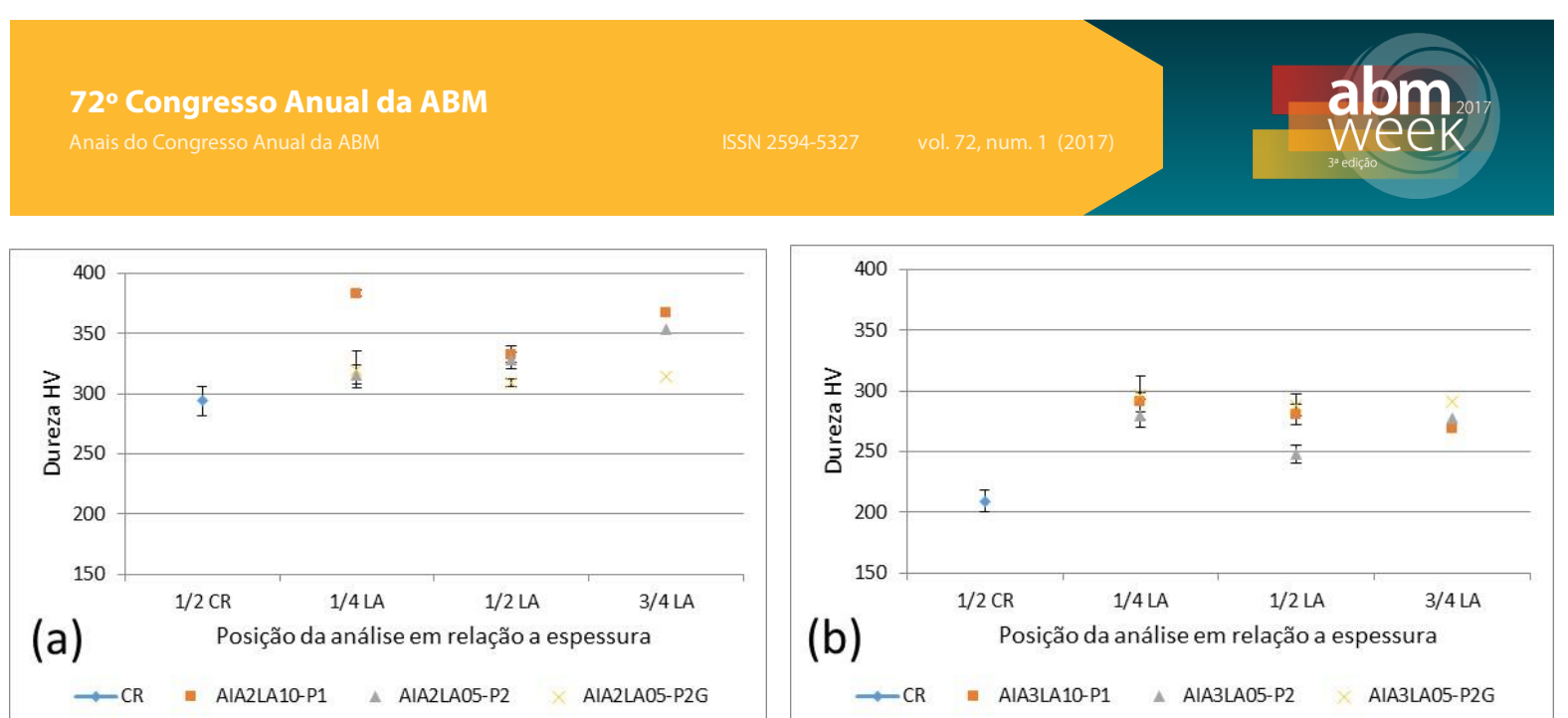

Figura 2. Ensaio de Microdureza Vickers das amostras em uma seção paralela à direção de laminação assimétrica (LA) com 1 passe de 10\% (A) AIA 201LN; (B) AIA 304L.

Tais comportamento de incremento da dureza se explicam pela assimétrica de deformação dada pelos diferentes diâmetros de cilindros empregues na laminação, e em contato cada um com uma distinta face da chapa o que resulta em diferentes arcos de contato com cada passe e por fim diferenciadas frentes de deformação com a redução da espessura. Por outro lado, o giro da amostra de $180^{\circ}$ em relação ao seu eixo DL contribui efetivamente para eliminar o caráter assimétrico imposto pelo primeiro passe.

\subsection{Microscópio Eletrônico de Varredura}

Com o intuito de melhor entendimento do que ocorreu com a microestrutura após o processo de laminação assimétrica, tem-se na Figura 3 as micrografias das amostras como recebida realizadas no trabalho prévio de Silva (2017), onde verificase que os aços 304L e 201LN (Figura 3a,b) possuem uma microestrutura de matriz austenítica com presença de maclas de recozimento sem a observação da presença de martensita. Sendo o tamanho de grão do aço 304LN ligeiramente inferior ao do 201LN.
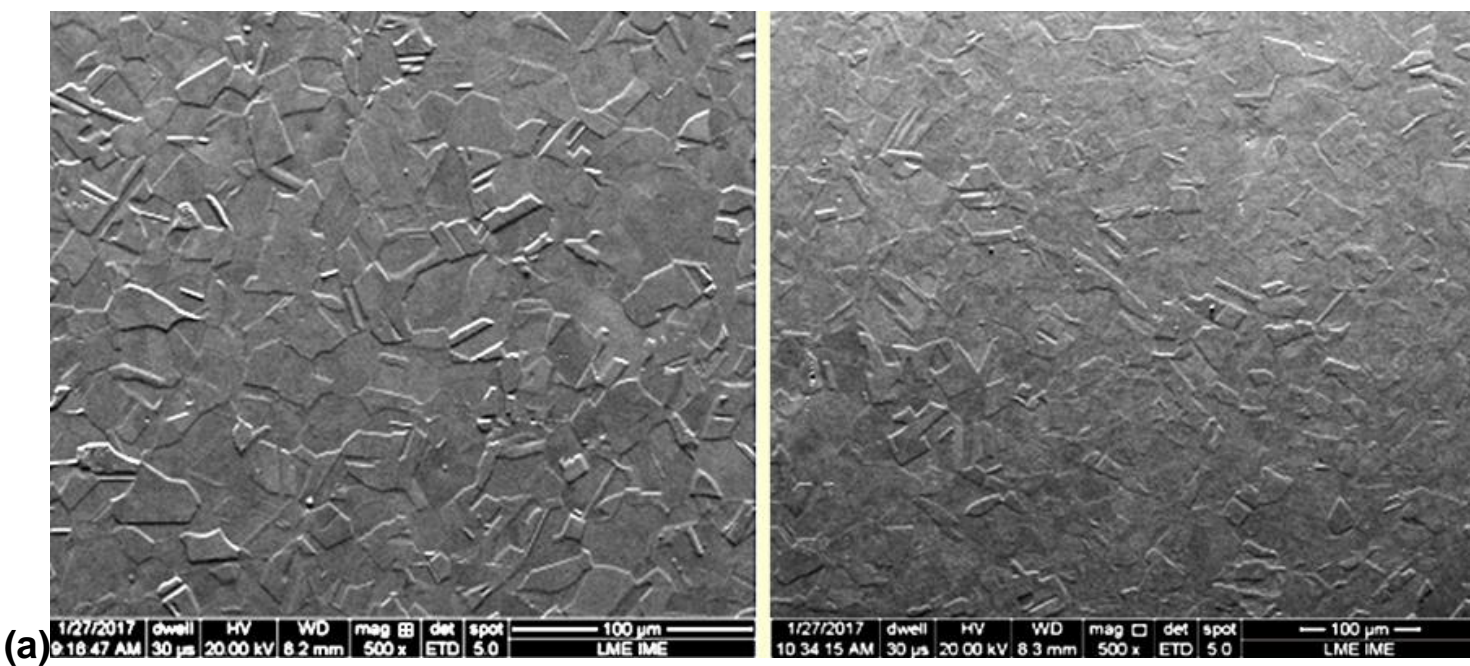

Figura 3. Micrografia em MEV com uso de detector de elétrons secundários dos materiais como recebido completamente austeníticos. (a) 201LN (500X) e (b) 304L (500X)

Em face as diferenças entre os valores de durezas apresentados a meia espessura para as distintas condições de laminação assimétrica para ambos os aços, e o número significativo de resultados, foram selecionadas somente as imagens de $1 / 2$ espessura para caracterizar tal evolução microestrutural. Nas Figuras de 4 a 15 são 
apresentadas as micrografias obtidas após o processo de laminação assimétrica, a partir de um MEV das amostras AIA2LA10-P1, AIA2LA05-P2, AIA2LA05-P2G, AIA3LA10-P1, A3LA05-P2, AIA3LA05-P2G, respectivamente. Com base nas observações no MEV foram obtidas imagens com maior nitidez quando somente polidas eletroliticamente com detector de elétrons retroespalhados e já as posteriormente atacadas para revelar a microestruturas os melhores resultados deram-se com o detector de elétrons secundários, em ambos os casos com uso de tensão de aceleração mais baixa $(10 \mathrm{KV})$, spot de 5,0 e distancia de trabalho de aproximadamente $10 \mathrm{~mm}$ em um MEV com filamento de emissão de campo (FEG).

(a)
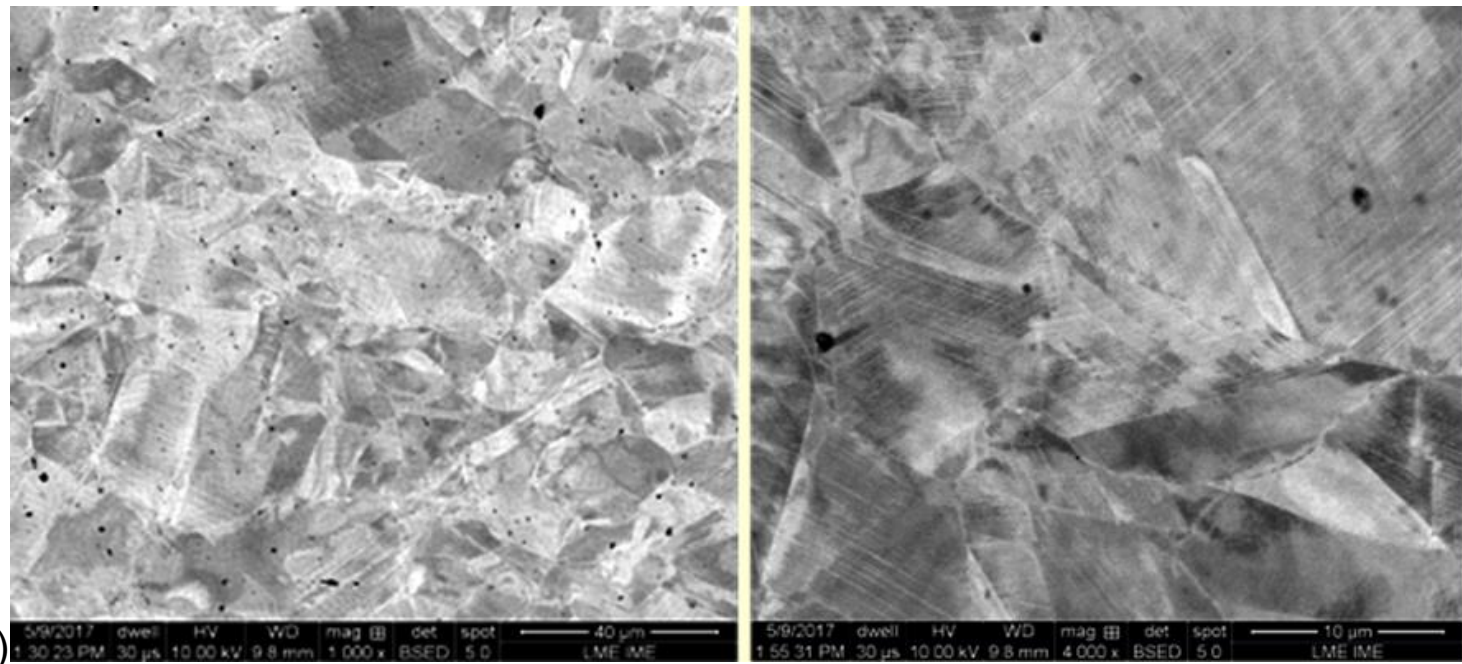

(b)

Figura 4. Micrografia da Amostra AIA2LA10-P1 em MEV elétrons retroespalhados: (a) Amostra polida (1000x). (b) Amostra polida (4000x).

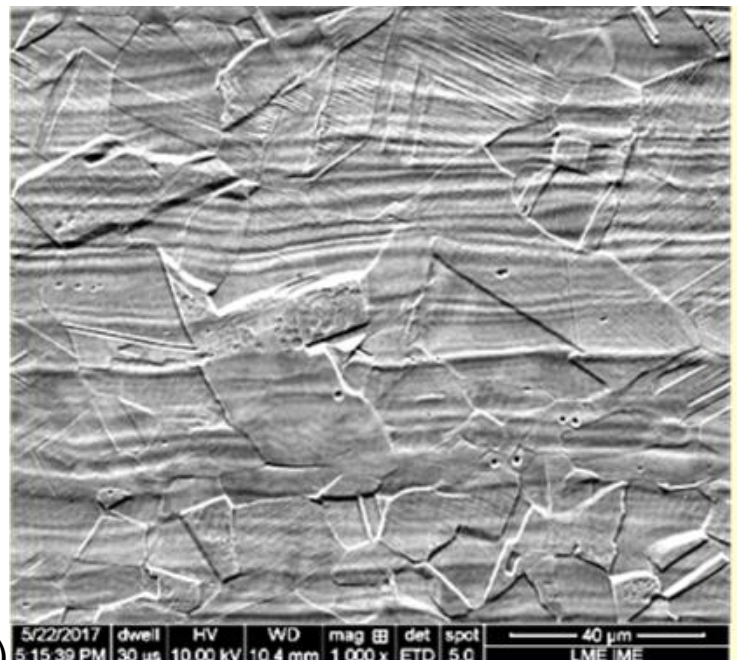

(a)

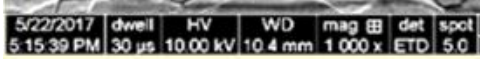

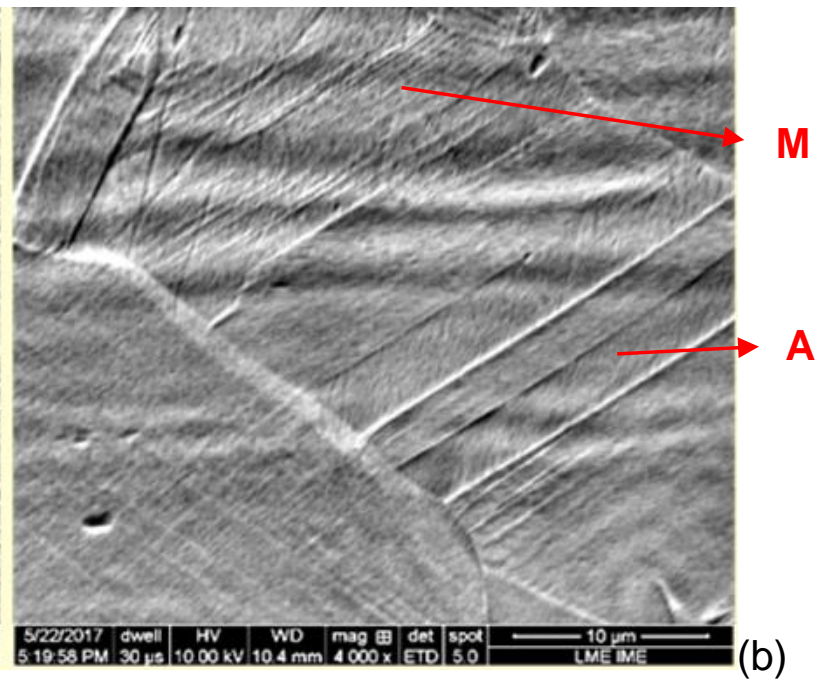

(b)

Figura 5. Micrografia da Amostra AIA2LA10-P1 em MEV elétrons secundários: (a) Amostra atacada (1000X). (b) Amostra atacada (4000x). 


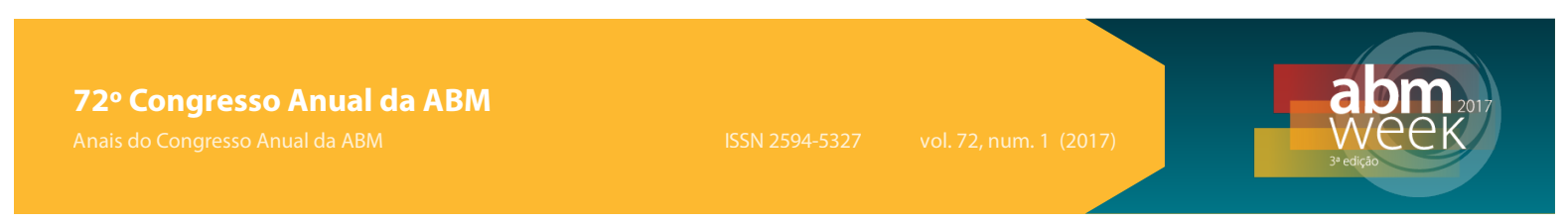

(a)
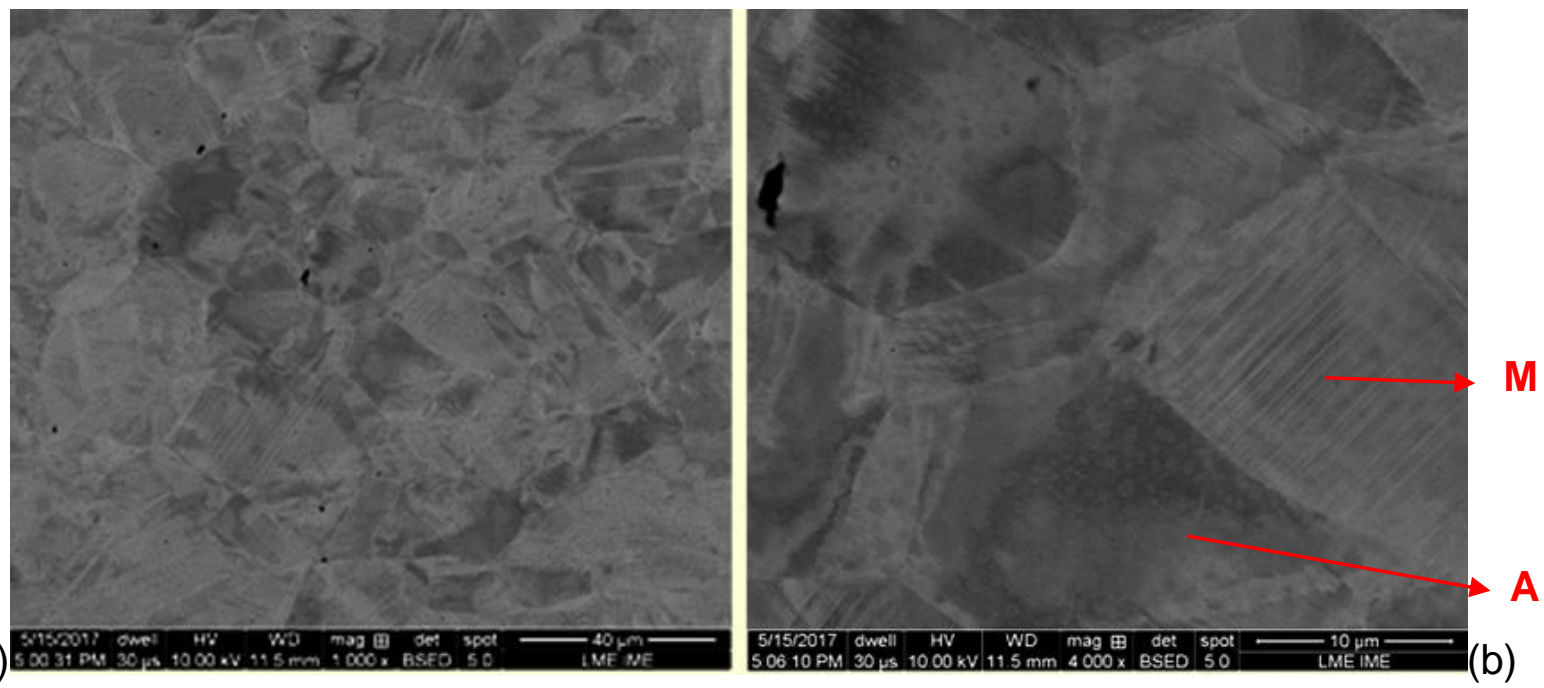

Figura 6. Micrografia da Amostra AIA2LA05-P2 em MEV elétrons retroespalhados: (a) Amostra polida (1000x). (b) Amostra polida (4000x).
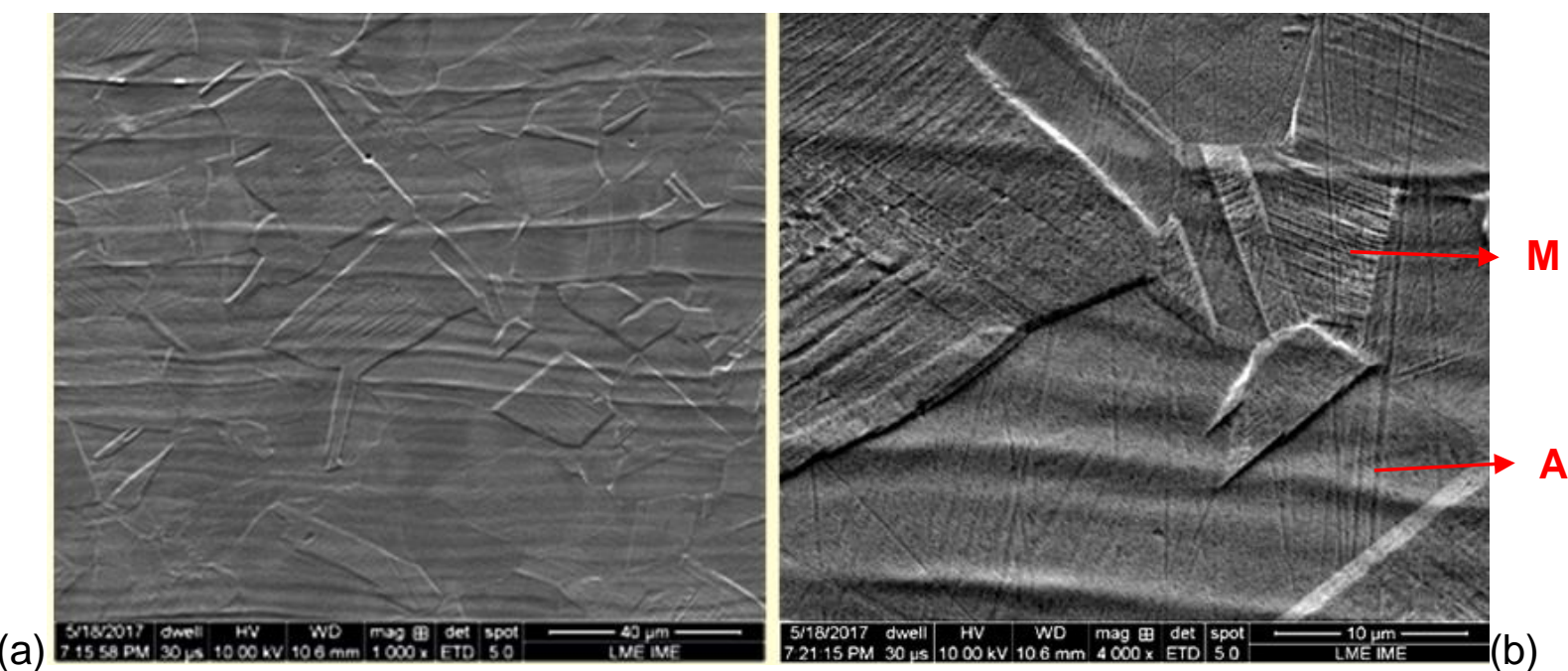

Figura 7. Micrografia da Amostra AIA2LA05-P2 em MEV elétrons secundários: (a) Amostra atacada

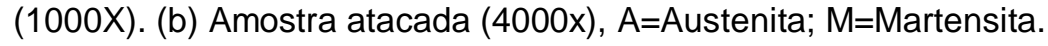
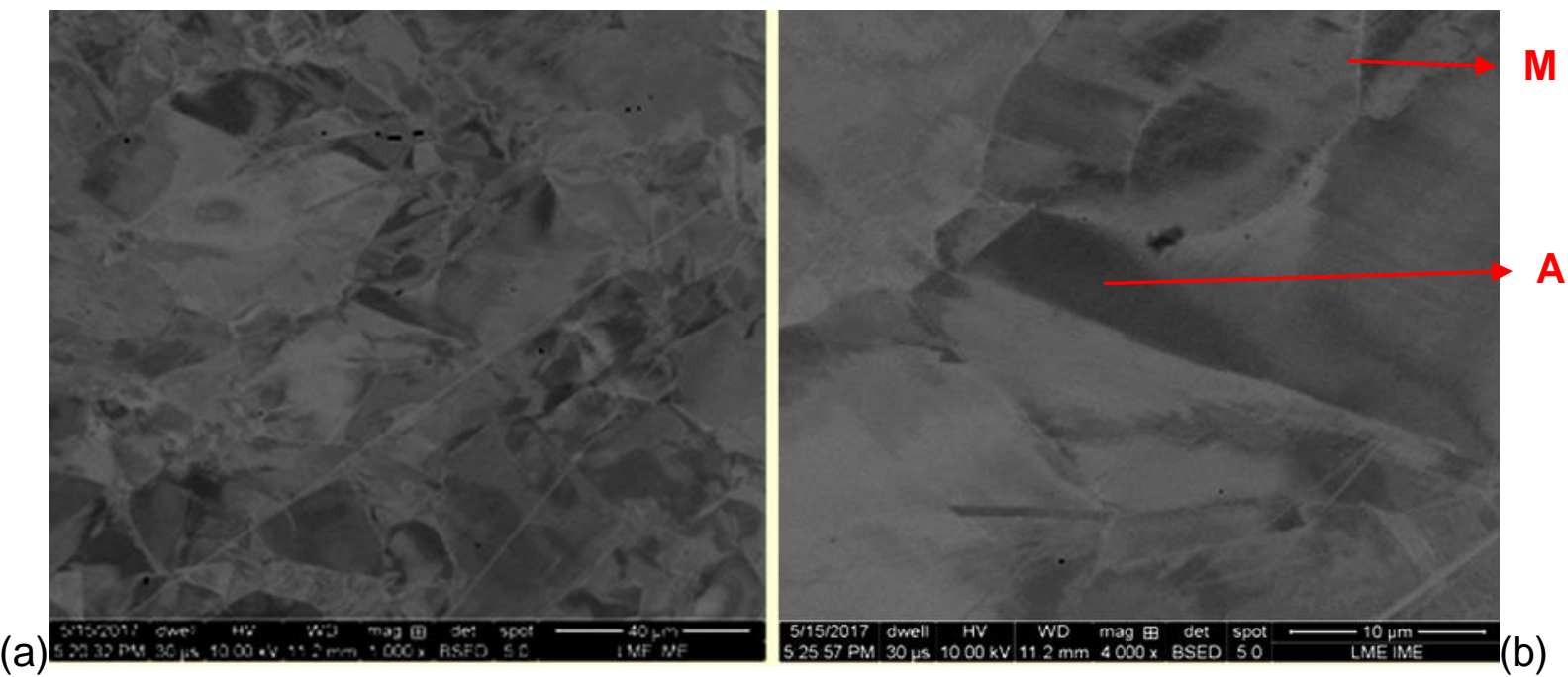

Figura 8. Micrografia da Amostra AIA2LA05-P2G em MEV elétrons retroespalhados: (a) Amostra polida (1000x). (b) Amostra polida (4000x). 
(a)
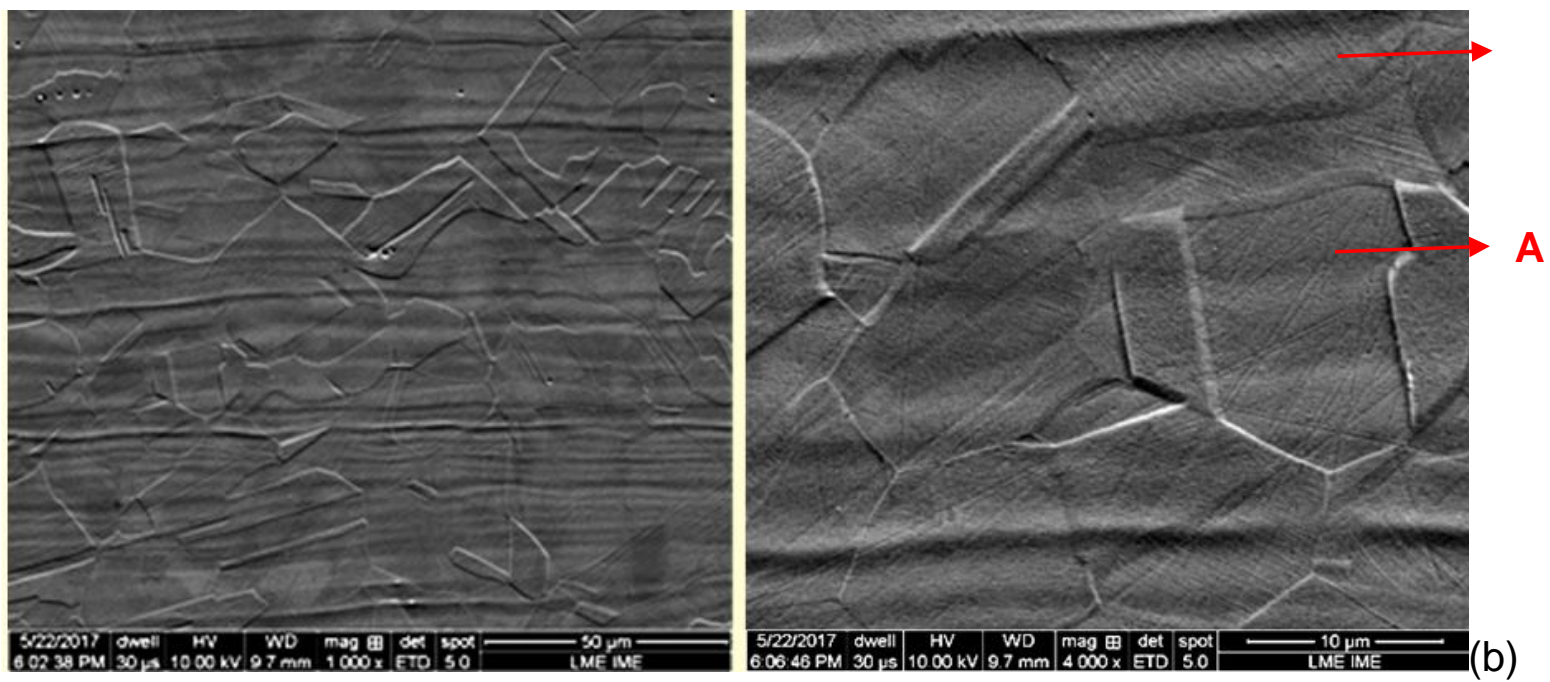

Figura 9. Micrografia da Amostra AIA2LA05-P2G em MEV elétrons secundários: (a) Amostra atacada

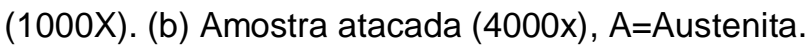
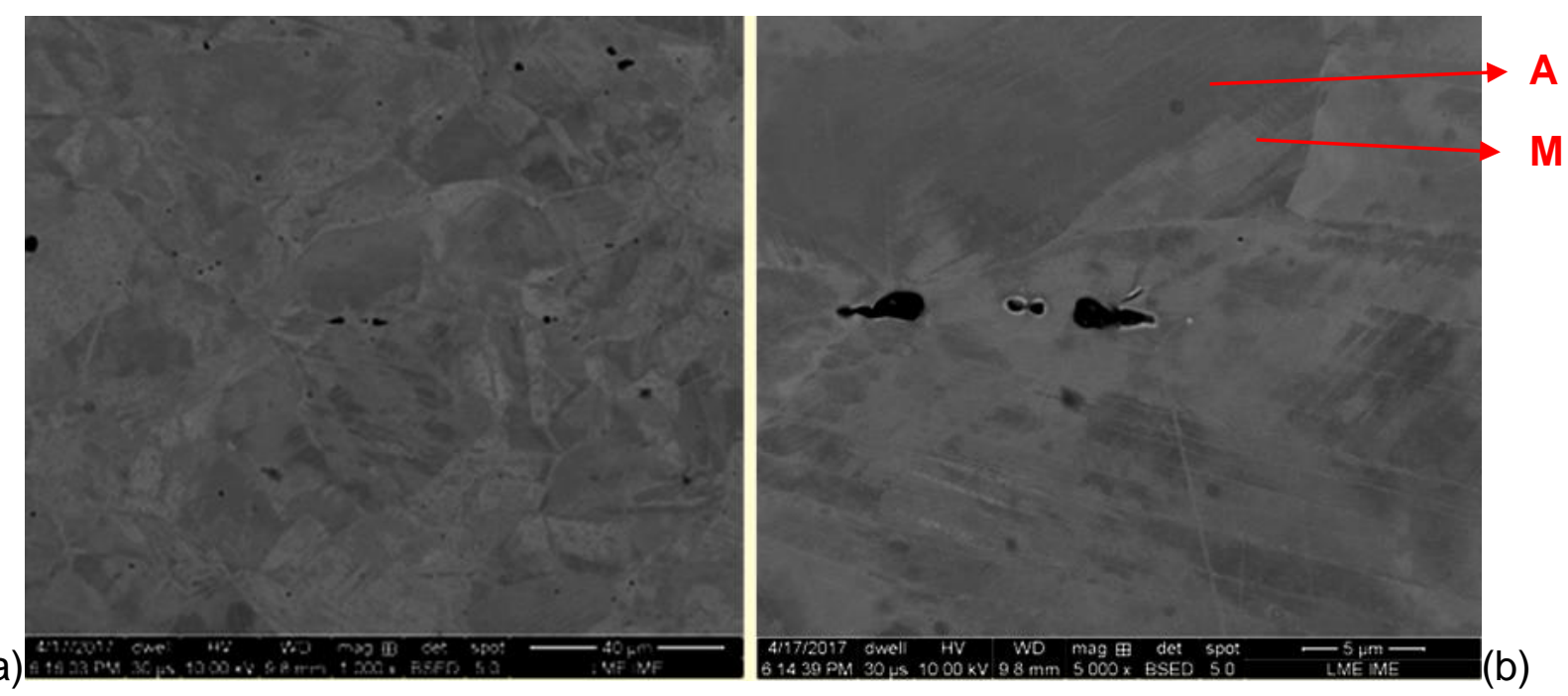

Figura 10. Micrografia da Amostra AIA3LA10-P1 em MEV elétrons retroespalhados: (a) Amostra polida (1000x). (b) Amostra polida (4000x).
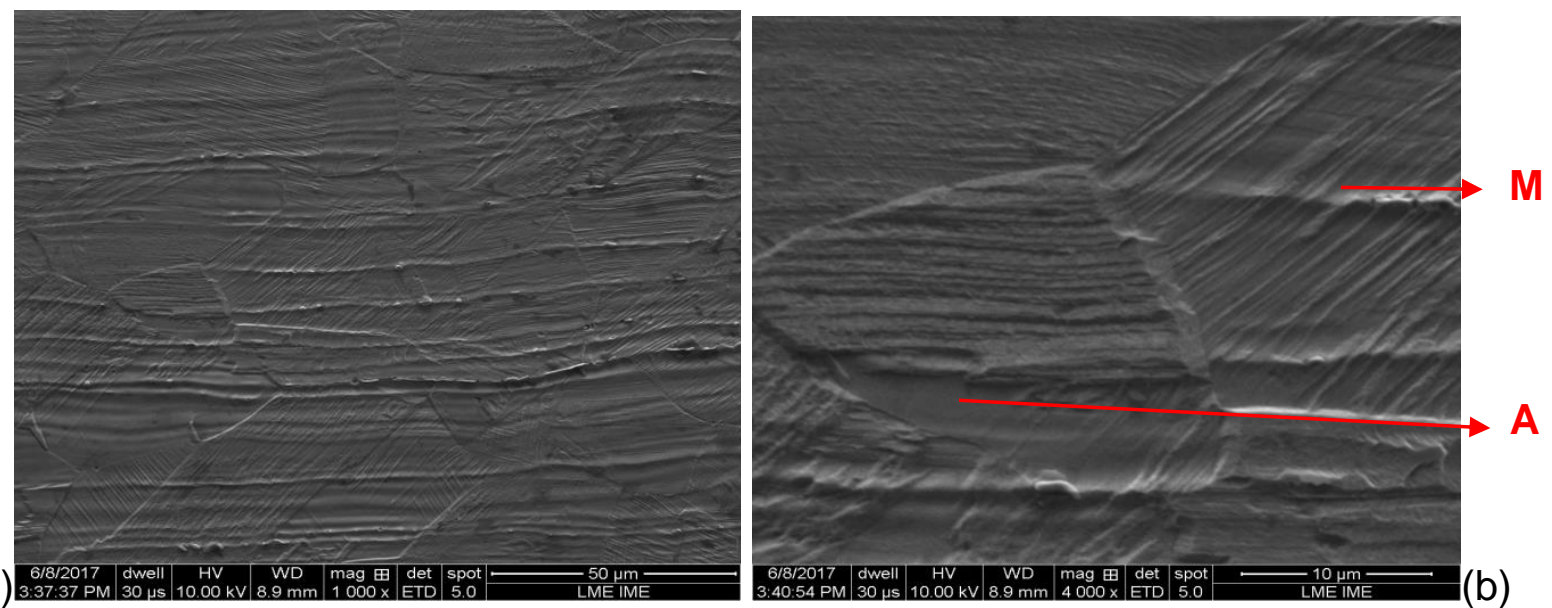

Figura 11. Micrografia da Amostra AIA3LA10-P1 em MEV elétrons secundários: (a) Amostra atacada (1000X). (b) Amostra atacada (4000x), M=Martensita. 

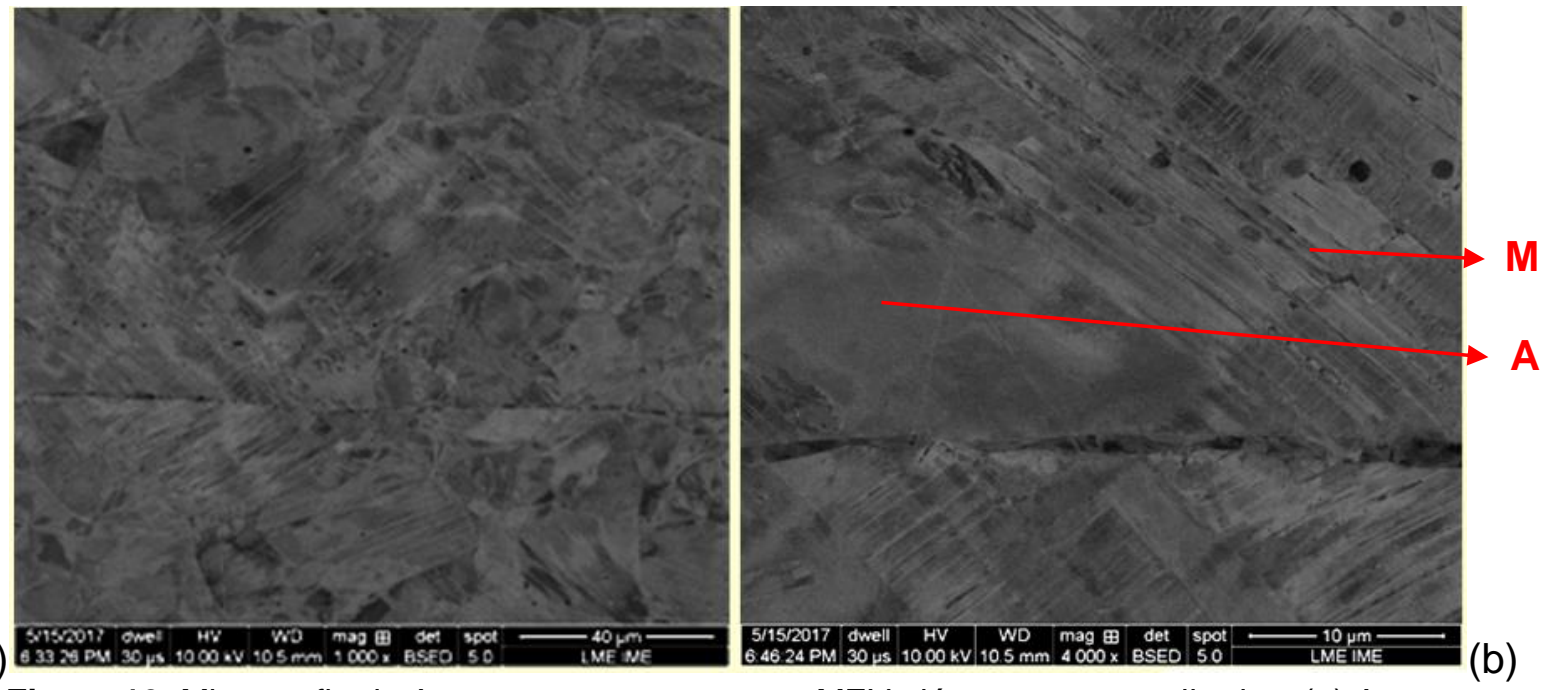

Figura 12. Micrografia da Amostra AIA3LA05-P2 em MEV elétrons retroespalhados: (a) Amostra polida (1000x). (b) Amostra polida (4000x), M=Martensita.

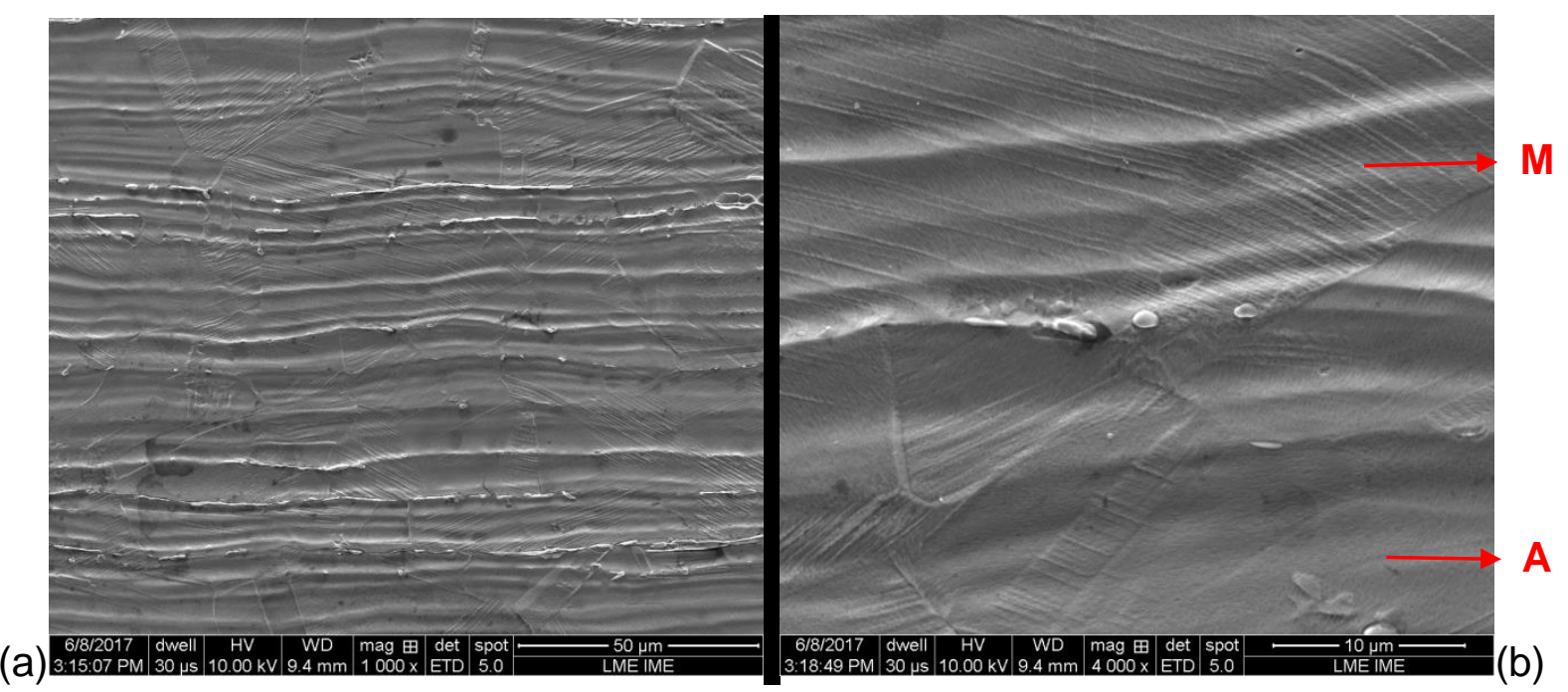

Figura 13. Micrografia da Amostra AIA3LA05-P2 em MEV elétrons secundários: (a) Amostra atacada

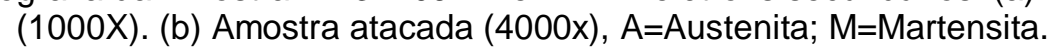

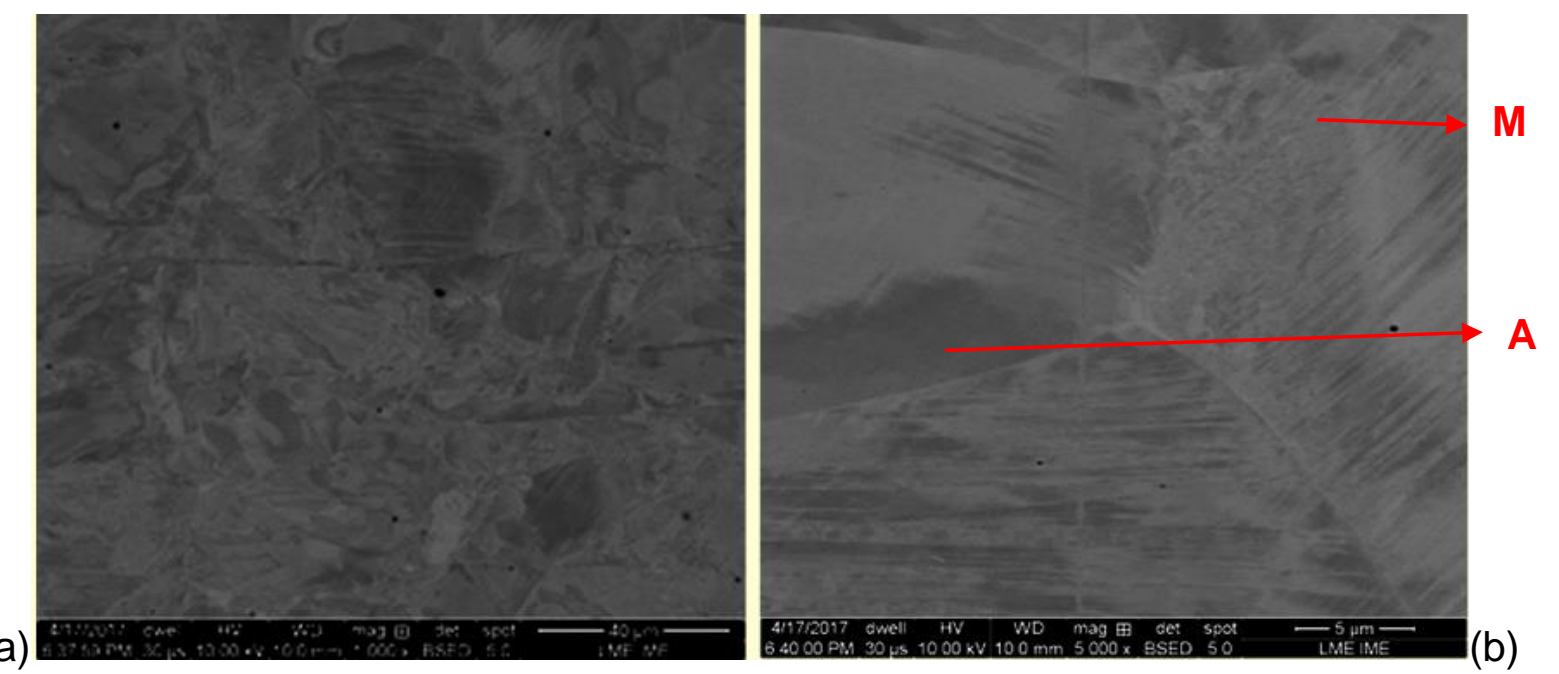

Figura 14. Micrografia da Amostra AIA3LA05-P2G em MEV elétrons retroespalhados: (a) Amostra polida (1000x). (b) Amostra polida (4000x). 
(a)
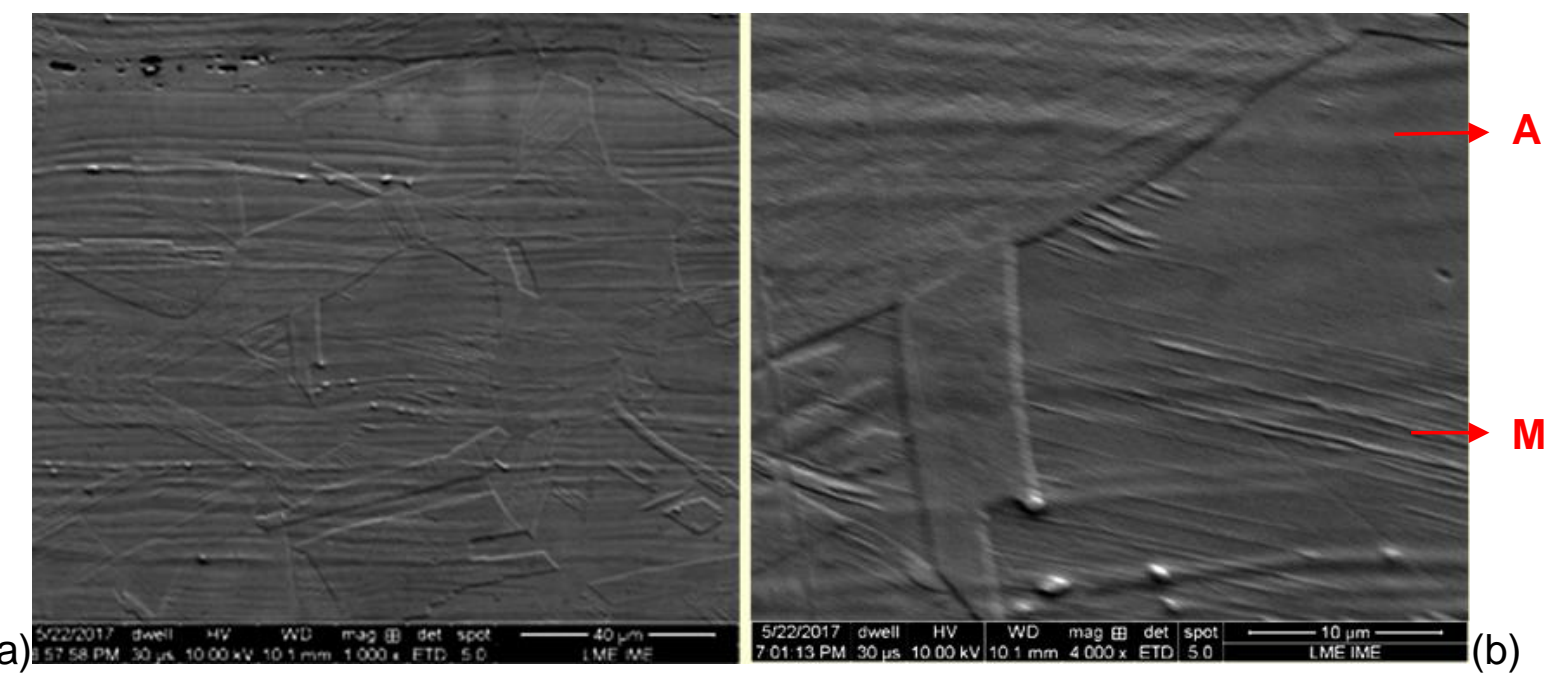

Figura 15. Micrografia da Amostra AIA3LA05-P2G em MEV elétrons secundários: (a) Amostra atacada (1000X). (b) Amostra atacada (4000x), $A=A$ ustenita; $M=$ Martensita.

Nas imagens de MEV por elétrons retroespalhados das amostras polidas é possível notar grãos de austenita prévia em conjunto com maclas. Percebe-se também a existência de agulhas de martensita não muito pronunciadas, estando mais bem ressaltadas nas amostras com dois passes de $5 \%$ sem giro.

Com as amostras atacadas, a microestrutura apresentou-se mais detalhada, ou seja, melhor revelada, através de uma análise por elétrons secundários, onde se verificou a presença de linhas onduladas paralelas à direção de laminação, possivelmente associadas à redução da espessura resultante da laminação à temperatura ambiente. Tais linhas são mais expressivas no aço 201LN, possivelmente por apresentar maior expoente de encruamento, devido à adição de $\mathrm{Mn}$ substituindo parte do $\mathrm{Ni}$, como estabilizador da austenita.

É possível notar no interior de grãos de amostras atacadas, particularmente as que sofreram dois passes de $5 \%$ sem giro, agulhas finas e paralelas de martensita formada por deformação. Em alguns casos, as agulhas chegam a atravessar o grão de um contorno a outro, e em outros possuem maior espessura, aparecendo junto aos contornos de grãos e se estreitando em direção ao centro do grão.

De forma a melhor elucidar e compreender os resultados apresentados com mais clareza pretende-se dar continuidade deste trabalho através de medidas de difração de raios- $X$ (DRX) nas distintas faces de cada uma das amostras (a fim de quantificar as fases presentes) e análise ao longo da espessura de forma mais criteriosa com um ultramicrodurômetro instrumentado e medidas de difração de elétrons retroespalhados (EBSD) no MEV / FEG.

\section{CONCLUSÃO}

Nas amostras, após sofrerem o processo de laminação assimétrica, observou-se a formação de martensita por deformação, sendo evidenciada nas micrografias obtidas por microscopia eletrônica ao longo do trabalho, nas distintas condições do processamento e também pelo incremento significativo nas durezas macro e micro das amostras. No entanto, foi através da microdureza, que foi possível constatar a presença do caráter assimétrico resultante da deformação imposta nos materiais em estudo.

\section{Agradecimentos}


Os autores agradecem a Aperam pela disponibilização do material. L.B. Balthazar agradece o financiamento da Bolsa de VC, além de agradecer aos doutorados Saulo B Diniz, Camila O Souza e Juciane M Alves pela a disponibilidade e ajuda de informações previas durante a realização deste trabalho. Ao IME pelos recursos para preparação e caracterização microestrutural. Ao Professor M.C. Júlio Cesar Soares de Oliveira que dispensou seu tempo em projetar o aparato de polimento eletrolítico instalado no Laboratório de Metalografia do IME. A.S.P. agracede a bolsa de produtividade à pesquisa (PQ-2) do CNPq (Processo 307798/2015-1).

\section{REFERÊNCIAS}

1 Lo KH, Shek $\mathrm{CH}$, Lai JKL. Recent developments in stainless steels, Materials Science and Engineering, Vol. R65, pp. 39-104, 2009.

2 Outokumpu Handbook of Stainless Steel [Livro]. - 2013.

3 ASM International Austenitic Stainless Steels [Seção do Livro], Stainless Steels for Design Engineers, 2008.

4 Oshima T, Habara Y, Kuroda K. Efforts to Save Nickel in Austenitic Stainless Steels, ISIJ International, Vol. 12, pp. 359-36, 2007.

5 ISSFa, "New 200-series" steels: An opportunity or a threat to the image of stainless steel, 2005.

6 Hamada AS, Karjalainen LP, Misra, RDK, Talonen J. Contribution of deformation mechanisms to strength and ductility in two $\mathrm{Cr}-\mathrm{Mn}$ grade austenitic stainless steels, Materials Science \& Engineering A, Vol. 559, pp. 336-344, 2013.

7 Chuaiphan W, Srijaroenpramong L. Effect of welding speed on microstructures, mechanical properties and corrosion behavior of GTA-welded AISI 201 stainless steel sheets, Journal of Materials Processing Technology, Vol. 214, pp. 402408, 2014.

8 HEDAYATI A.; NAJAFIZADEH, A.; KERMANPUR, A.; FOROUZAN, F. The effect of cold rolling regime on microstructure and mechanical properties of AISI 304L stainless steel, Journal of Materials Processing Technology, Vol. 210, pp. 1017-1022, 2010.

9 BEHJATI P., KERMANPUR A. e NAJAFIZADEH A. Application of Martensitic Transformation Fundamentals to Select Appropriate Alloys for Grain Refining Through Martensite Thermomechanical Treatment [Artigo] // Metallurgical and Materials Transactions: The Minerals, Metals \& Materials Society and ASM International, 2013. - vol. 44A. - pp. 3524-3531.

10 Shin $\mathrm{HC}, \mathrm{Ha}$ TK, Chang W. Kinetics of deformation induced martensitic transformation in a 304-stainless steel, Scripta Materialia, pp. 823-829, 2001.

11 Shirdel M, Mirzadeh H, Parsa MH. Nano/ultrafine grained austenitic stainless steel through the formation and reversion of deformation-induced martensite: Mechanisms, microstructures, mechanical properties, and TRIP effect, Materials Characterization, Vol. 103, pp. 150-161, 2015.

12 Zuo, Fang - Qing et al. Shear Deformation and Grain Refinement in Pure Al by Asymmetric Rolling.Transactions of Nonferrous Metals Society of China, Changhai, China: Science Press, número 18, p. 774 - 777, 2008.

13 Alves JM. Quantificação de fase e tensão residual em aço trip após deformação por laminação e tração [Dissertação de mestrado]. Rio de Janeiro: Instituto Militar de Engenharia - IME; 2015. 
14 De Souza CO. Desenvolvimento de estrutura de grãos ultrafinos em aço inoxidável 201ln via múltiplas etapas de laminação a frio e recozimento para reversão [Dissertação de mestrado]. Rio de Janeiro: Instituto Militar de Engenharia - IME; 2016.

15 Silva CS. Formação e reversão da martensita induzida por deformação nos aços inoxidáveis austeníticos 304L e 201LN [Dissertação de mestrado]. Rio de Janeiro: Instituto Militar de Engenharia - IME; 2017. 